\title{
Exit Strategy from COVID-19: Vaccination and an Alternative Solution
}

\author{
Indrani Roy ${ }^{1}$
}

${ }^{1}$ Affiliation not available

July 9, 2021

\begin{abstract}
Vaccination groups all over the globe made a strong coordinated effort to put an end to the current COVID-19 crisis. Since vaccination started first in the UK on 8 th December, 2020 we have sufficient data to analyse and derive useful results. It addressed issues viz. seasonality, indirect consequences of mass vaccination and fast mutation of the virus after mass vaccination. To develop useful timely insights, some similarities between COVID-19 and Flu received attention. Critical and open analyses, balanced discussion in the current crucial stage are desperately needed. Questioning, debating and criticism are always the basis of good science and the main pillars to its advancement. With that objective in mind, it is an effort to explore areas relating to the effectiveness of COVID-19 vaccines with a pragmatic viewpoint. Policymakers will be greatly benefitted from such analyses. An alternative optimistic pathway is also mentioned which was proposed as early as 17 th March, 2020 and is practically without side effects and no vested interest involved.
\end{abstract}

\section{Hosted file}

BioSymp.pdf available at https://authorea.com/users/336178/articles/529658-exit-strategyfrom-covid-19-vaccination-and-an-alternative-solution 